\title{
Effects of the plane of nutrition for grower pigs on their grow-finish performance and meat quality in winter
}

\author{
Bo-Seok Yang ${ }^{1}$, Myeong Hyeon Kim ${ }^{1}$, Jung-Seok Choi ${ }^{2}$, Sang Keun Jin ${ }^{1,3}$, Man-Jong Park ${ }^{1}$, \\ Young-Min Song ${ }^{1}$ and Chul Young Lee ${ }^{1,3^{*}}$ \\ ${ }^{1}$ Department of Animal Resources Technology, Gyeongnam National University of Science and Technology, Jinju 52725, Korea \\ ${ }^{2}$ Swine Science and Technology Center, Gyeongnam National University of Science and Technology, Jinju 52725, Korea \\ ${ }^{3}$ Regional Animal Industry Center, Gyeongnam National University of Science and Technology, Jinju 52725, Korea
}

\begin{abstract}
Little is known about the effects of the plane of nutrition on growth performance and meat quality of grow-finish pigs under commercial production conditions. The present study was thus addressed to this virtually unanswered question. One hundred and two barrows and 102 gilts weighing approximately $24 \mathrm{~kg}$ were fed phase I and II grower diets with a high, medium, or low plane of nutrition (HP, MP, or LP) to approximately 43 and $70 \mathrm{~kg}$, respectively, in 6 replicates (pens). Subsequently, the HP and MP groups were fed the HP and MP1 finisher diets, respectively, the LP group being fed a second MP (MP2) finisher diet (LP1 group). Moreover, 68 LP-grower-fed barrows and gilts were added to the feeding trial and fed the MP1 and LP finisher diets to approximately $95 \mathrm{~kg}$ and thereafter, respectively (LP2 group). All MP diets had the lysine:calorie ratios comparable to the RNC recommendations, with $<18 \%$ differences between those of the HP and LP diets. The finisher pigs were reared in 16 pens and slaughtered at approximately $115 \mathrm{~kg}$. The gain:feed ratio, but not average daily gain (ADG), was greater for the HP group than for the MP and LP during the grower phase I whereas during the grower phase II, ADG was greater $(p<0.05)$ for the HP and LP groups vs. MP. During the finisher phase I, ADG was less for the LP (LP1 + LP2) group vs. HP and MP, with no difference between the HP and MP groups; the gain:feed ratio was less for the LP vs. MP group. Backfat thickness was greater for the LP vs. HP group. The water holding capacity of fresh longissimus dorsi muscle (LM) and the sensory juiciness score for cooked LM were greatest for the LP group, the sensory flavor and tenderness scores being greater for the LP group vs. MP. In conclusion, results suggest that compensatory growth occurred for the LP and MP groups during the grower phase II and finisher phase I, respectively, with fat deposition increased for the LP group and that meat quality could be improved by the use of LP.
\end{abstract}

Keywords: Backfat, Growing-finishing pig, Growth, Meat quality, Plane of nutrition, Winter

\section{Introduction}

Received: Nov 22,2018 Revised: Jan 10,2019 Accepted: Jan 14,2019

"Corresponding author: Chul Young Lee, Department of Animal Resources Technology, Gyeongnam National University of Science and Technology, Jinju 52725, Korea.

Tel: +82-55-751-3285,E-mail: cylee@gntech.ac.kr

This is an Open Access article distributed under the terms of the Creative Commons Attribution Non-Commercial License (http://creativecommons.org/licenses/by$\mathrm{nc} / 4.0 /$ ) which permits unrestricted non-commercial use, distribution, and reproduction in any medium, provided the original work is properly cited.

Copyright (C) 2019 Korean Society of Animal Science and Technology. 
primarily by the energy concentration and lysine:calorie ratio of the diet provided to the animals [1-4]. The lean gain rate of the grower pigs, in general, increases with increasing dietary energy intake, whereas in the finisher pigs, the lean increases with a reduced lean gain:energy ratio compared with that of the grower pigs, with the excess energy partitioned for fat deposition [5-8]. Moreover, the energy intake and hence the fat deposition rate of the finisher pig increase with the increasing dietary energy density even though the reverse is true for the feed intake $[1,9,10]$. The energy density and lysine:calorie ratio of the grower diets are therefore maximally increased based on these relationships between the plane of nutrition and growth. For the finisher diets, however, the lysine:calorie ratios are set at lower levels than those of the grower diets, with the energy concentrations set at levels equal to or lower than those of the latter.

When the dietary lysine:calorie ratio for the grower pigs is lower than that supporting the maximum lean gain, the rate of weight gain of the pigs decreases but the gain:feed and gain:lysine intake ratios increase $[11,12]$. Furthermore, a compensatory growth usually occurs when the grower pigs fed a diet with a low lysine:calorie ratio switch to a diet with a normal lysine:calorie ratio. The compensatory growth is frequently, but not always, concomitant with an increased feed intake and an increased fat deposition [13, 14], even though the fat deposition can be down-regulated during the compensatory growth for a compensatory lean gain which has priority over the energy retention [11,15-19].

The present experimenters have reported in a previous study that pigs which had been placed on grower diets with low planes of nutrition during the hot summer season exhibited a greater feed intake, a greater weight gain rate, and a greater backfat thickness in fall than those which had been reared on a high plane of nutrition [20]. However, it was not possible in that study to separate the nutritional effects from those of the seasonal effects, because the compensatory growth observed in the pigs reared on the low plane of nutrition resulted not only from the low-plane nutrition but also from the heat stress $[8,21]$. The growing-finishing pigs were therefore reared on varying planes of nutrition in winter under commercial production conditions in the present study, thereby investing the effects of the plane of nutrition during the grower phase on growth performance during the grower and subsequent finisher phases as well as meat quality.

\section{Materials and Methods}

\section{Experimental diets and animals}

All experimental protocols involving animals were approved by the Institutional Animal Care and Use Committee (IACUC) of Gyeongnam National University of Science and Technology. A total of 204 66-day-old (Landrace $\times$ Yorkshire) $\times$ Duroc barrows and gilts weighing approximately $24 \mathrm{~kg}$ were randomly distributed to 6 pens according to the sex, with 34 pigs per pen, on December 31,2017 on a commercial farm such that each of the three experimental groups with the high, medium, and low planes of nutrition (HP, MP, and LP, respectively), respectively, had two pens of both sexes. The grower pigs were provided with the commercial phase I grower diets with HP, MP, and LP for 29, 30, and $32 \mathrm{~d}$, respectively, followed the grower phase II diets with the respective planes of nutrition for 28, 30, and $31 \mathrm{~d}$, respectively (Table 1 ).

The pigs from each grower pen were divided into two finisher pens at the end of the grower phase II. The pigs which had been placed on HP and MP were provided with the HP and MP1 finisher diets (HP and MP groups, respectively), respectively; the pigs which had been placed on LP during the grower phase were provided with the MP2 finisher diet (LP-1 group; Table 1). In addition, a total of 68 contemporary pigs consisting of equal numbers of barrows and gilts which had been placed on LP during the entire grower phase were newly added to the on-going feeding trial and provided with the MP1 and LP finisher diets for $22 \mathrm{~d}$ of the finisher phase I and the rest (phase II) of the feeding trial (LP-2 group), respectively. The energy and lysine concentrations of all the MP diets used in the present feeding trial were comparable to the NRC [22] recommendations, with the difference in the lysine:calorie ratio between each pair of the HP and LP diets not exceeding $18 \%$.

All animals were weighed by the unit of pen on day 0 of the grower phase I to minimize the stress of the young pigs, but the body weight was measured individually on the beginning day of the grower phase II and onward. As such, the average daily gain

Table 1. Energy and lysine concentrations of the experimental diets (as-fed basis)

\begin{tabular}{|c|c|c|c|c|c|c|c|c|c|c|}
\hline \multirow{2}{*}{ Item } & \multicolumn{3}{|c|}{ Grower phase I } & \multicolumn{3}{|c|}{ Grower phase II } & \multicolumn{4}{|c|}{ Finisher } \\
\hline & HP ${ }^{1)}$ & MP') $^{2)}$ & LP $^{3)}$ & HP & MP & LP & HP & MP1 & MP2 & LP \\
\hline ME (Mcal/kg) & 3.34 & 3.30 & 3.26 & 3.35 & 3.33 & 3.25 & 3.35 & 3.25 & 3.25 & 3.25 \\
\hline Total Lys (\%) & 1.20 & 1.10 & 1.00 & 1.10 & 1.02 & 0.93 & 0.90 & 0.80 & 0.85 & 0.72 \\
\hline Lys:ME (g/Mcal) & 3.59 & 3.33 & 3.07 & 3.29 & 3.06 & 2.86 & 2.69 & 2.46 & 2.62 & 2.22 \\
\hline
\end{tabular}

\footnotetext{
${ }^{1-3)}$ Commercial diets with high, medium, and low planes of nutrition, respectively.
}

$\mathrm{HP}$, high plane; MP, medium plane; LP, low plane; ME, metabolizable energy. 
(ADG) for each pen during the grower phase I was calculated by dividing the total weight gain by the total number of days on feed of all pigs, with dead or culled animals excluded from the calculation, whereas for the grower phase II and the finisher phase, individual body weights were used for the ADG calculation. The average daily feed intake per pig (ADFI) for each pen was calculated by dividing the total feed intake by the total number of days on feed in both grower and finisher phases. The final body weights and feed intakes of the HP, MP, LP1, and LP-2 groups were measured on $171,173,178$, and $180 \mathrm{~d}$ of age, respectively.

The experimental animals were transported to a local abattoir and slaughtered after the feeding trial on 4 days for the 4 experimental groups, respectively, 35 outgrown animals having been slaughtered at $157 \mathrm{~d}$ of age before the termination of the feeding trial. The backfat thickness of the carcasses was corrected for a 115$\mathrm{kg}$ final weight using 0.26 and $0.19 \mathrm{~mm}$ per $\mathrm{kg}$ body weight for the barrow and gilt, respectively, which were obtained by the analysis of regression of the variable on the live weight.

\section{Physicochemical analysis and sensory evaluation}

A total of 30 animals weighing approximately $115 \mathrm{~kg}$, with 5 animals per sex $\times$ dietary group, were selected prior to the transport to the abattoir. The upper half of the left-side longissimus dorsi muscle (LM) was cut from the carcasses on the following day of slaughter and transported to the laboratory. The LM was not collected from the LP1 group because of a limited capacity of physicochemical and sensory analyses on a given day.

The lightness and redness of LM were measured according to the CIE [23] L* and a* standards. Other physicochemical characteristics of LM, including the contents of the moisture, protein, and fat, were determined as previously described [24-26].

Sensory quality attributes of fresh LM were evaluated by nine panelists who had received training on sensory evaluation at least for six months within the Meat Science and Processing Laboratory. The sensory attribute was scored according to a 9-ladder whole number scale as previously described [25-27] in such a way that a greater score indicated better quality. The quality attributes of cooked LM also were evaluated by the 9-ladder scale as in the evaluation for fresh LM.

\section{Statistical analysis}

All data were analyzed using the SAS program (SAS Inst., Inc., Cary, NC, USA). The growth performance variables for the grower phase were analyzed using the MIXED procedure by partitioning the variation associated with the sex into the random effect, with the means for the planes of nutrition compared by the 'PDIFF' option. The data of growth performance during the finisher phase and carcass and LM characteristics were analyzed using the Gen- eral Linear Model procedure. The pen and the individual animal were the experimental units in all growth performance and postmortem variables, respectively, in these analyses, and the means for the planes of nutrition and sexes were compared by the preplanned contrast. In all comparisons and tests, the $p$-values of $<0.05$ and $<0.10$ were used as the criteria of the significance and tendency, respectively.

\section{Results}

\section{Growth performance}

During the grower phase I, the ADG and ADFI did not differ between the LP and HP groups or between the LP and MP groups (Table 2). The gain:feed ratio, however, was greater for the HP group than for the MP and LP groups, with no difference between the MP and LP groups. The daily intake of metabolizable energy (ME) did not differ among the HP, MP, and LP groups whereas the gain:ME ratio was greater for the HP group than for either of the MP and LP groups. The daily lysine intake did not differ among the three dietary groups, but the gain:lysine ratio was less for the MP group than for the HP and LP groups.

The ADG during the grower phase II was greater for the LP group than for the MP group, not being different between the LP and HP groups. There was no difference between the three dietary groups in any of the ADFI, gain:feed ratio, daily ME intake, gain:ME ratio, daily lysine intake, and gain:lysine ratio, but there was a tendency of a greater gain:lysine ratio for the LP group vs. $\operatorname{HP}(p=0.08)$ or $\mathrm{MP}(p=0.06)$ group.

The ADG was less for the LP (LP1 + LP2) group than for the $\mathrm{HP}$ or MP group as well as for the barrow than for the gilt during the finisher phase I (Table 3). The ADFI was greater for the barrow vs. gilt, but it did not differ between the LP group and either of the HP and MP groups. The gain:feed ratio, however, was greater for the MP group vs. LP as well as for the LP2 group vs. LP 1 .

There was no difference between the LP group and either of the HP and MP groups in any of the ADG, ADFI, and gain:feed ratio during the finisher phase II. The estimated number of days necessary to reach a $115-\mathrm{kg}$ market weight was greater for the LP group (175.0) than for the HP group (168.4), but it did not differ between the LP and MP (172.9) groups or between the LP-1 and LP-2 groups. Regarding the sex effect, the ADG and ADFI were greater for the barrow vs. gilt whereas the estimated number of days to the market weight was greater for the latter.

The dressing percentage of the carcass was greater for the LP group than for the MP group. The backfat thickness adjusted for a $115-\mathrm{kg}$ live weight was greater for the LP group $(22.9 \mathrm{~mm})$ than for the HP group $(21.4 \mathrm{~mm})$ as well as for the barrow $(24.0 \mathrm{~mm})$ vs. gilt $(20.5 \mathrm{~mm})$. 
Table 2. Effects of the plane of nutrition on growth performance of the grower pigs

\begin{tabular}{|c|c|c|c|c|c|}
\hline Item & HP & MP & LP & SEM & $p$-value \\
\hline \multicolumn{6}{|l|}{ Phase I $^{1)}$} \\
\hline Initial Wt (kg) & $23.5^{\mathrm{b}}$ & $24.7^{\mathrm{a}}$ & $23.2^{b}$ & 0.35 & 0.01 \\
\hline Days on feed & 29 & 30 & 32 & - & - \\
\hline Final Wt $(\mathrm{kg})$ & 42.6 & 43.5 & 42.7 & 0.45 & 0.44 \\
\hline ADG (g) & 663 & 632 & 612 & 15 & 0.25 \\
\hline ADFI (g) & 1,172 & 1,307 & 1,293 & 31 & 0.15 \\
\hline Gain:feed & $0.566^{\mathrm{a}}$ & $0.483^{b}$ & $0.474^{\mathrm{b}}$ & 0.009 & $<0.01$ \\
\hline ME intake (Mcal/d) & 3.91 & 4.31 & 4.21 & 0.10 & 0.19 \\
\hline Gain:ME (g/Mcal) & $169.5^{\mathrm{a}}$ & $146.4^{\mathrm{b}}$ & $145.3^{\mathrm{b}}$ & 2.7 & $<0.01$ \\
\hline Lys intake (g/d) & 14.06 & 14.37 & 12.93 & 0.34 & 0.16 \\
\hline Gain:Lys (g/g) & $47.17^{\mathrm{a}}$ & $43.93^{b}$ & $47.37^{\mathrm{a}}$ & 0.86 & 0.04 \\
\hline \multicolumn{6}{|l|}{ Phase $\|^{2)}$} \\
\hline Initial Wt (kg) & $43.1 \pm 0.9$ & $43.6 \pm 0.8$ & $43.0 \pm 0.9$ & - & 0.83 \\
\hline Days on feed & 28 & 30 & 31 & - & - \\
\hline Final Wt (kg) & $70.8 \pm 1.1$ & $71.0 \pm 1.1$ & $73.1 \pm 1.1$ & - & 0.26 \\
\hline$A D G(g)$ & $990 \pm 16^{a}$ & $907 \pm 15^{b}$ & $969 \pm 16^{a}$ & - & $<0.01$ \\
\hline ADFI (g) & 2,262 & 2,244 & 2,348 & 159 & 0.63 \\
\hline Gain:feed & 0.438 & 0.398 & 0.413 & 0.010 & 0.20 \\
\hline ME intake (Mcal/d) & 7.56 & 7.47 & 7.63 & 0.53 & 0.90 \\
\hline Gain:ME (g/Mcal) & 130.8 & 119.4 & 127.0 & 3.0 & 0.21 \\
\hline Lys intake (g/d) & 24.88 & 22.89 & 21.84 & 1.61 & 0.18 \\
\hline Gain:Lys (g/g) & 39.78 & 38.97 & 44.36 & 0.99 & 0.10 \\
\hline
\end{tabular}

${ }^{1)}$ Data are least squares means (LSM) of two replicates (pens) of 34 pigs.

${ }^{2)}$ Data are LSM or LSM \pm SEM of two replicates of 26 to 34 pigs.

${ }^{a, b}$ Means with no common superscript within a row differ $(p<0.05)$.

HP, high plane; MP, medium plane; LP, low plane; SEM, standard error of mean; Wt, weight; ADG, average daily gain; ADFI, average daily feed intake; ME, metabolizable energy.

\section{Meat quality attributes of LM}

The $\mathrm{pH}$ value of $\mathrm{LM}$ was greater for the $\mathrm{LP}$ group (5.66) than for the MP group (5.47; Table 4). The lightness $\left(\mathrm{L}^{*}\right)$ and redness $\left(\mathrm{a}^{*}\right)$ of LM did not differ between the LP group and either of the HP and MP groups. The water holding capacity (WHC) was greater for the LP group than for the HP and MP groups. Furthermore, WHC was greater for the barrow vs. gilt whereas the reverse was true for the drip loss. The cooking loss, shear force, cohesiveness, springiness, gumminess, and moisture content did not differ between the LP group and either of the HP and MP groups. The fat content was greater for the barrow than for the gilt; protein content was less for the LP vs. MP group, with no difference between the barrow and gilt. Moreover, the fat content was negatively correlated $(p<0.01)$ with the moisture and protein contents $(r=-0.64$ and -0.51 , respectively) and also tended to be positively correlated with the $\mathrm{pH}$ value ( $r=0.34 ; p=0.07$; data not shown).

The color score for fresh LM, which did not differ between the LP group and either of the HP and MP groups, was greater for the barrow than for the gilt in the sensory evaluation (Table 5). The scores for the aroma and drip did not differ between the LP group and the HP or MP group or between the sexes, but the off-odor score was less for the LP vs. MP group. The marbling and acceptability scores were greater for the barrow vs. gilt.

The sensory color score for cooked LM was greater for the barrow than for the gilt. The aroma score was greater for the LP than for the MP group. Scores for the flavor, tenderness, and acceptability were greater for the LP group than for the MP group. Moreover, the juiciness score was also greater for the LP group than for the HP as well as MP group. Regarding the sex effect, the color, flavor, juiciness, tenderness, and acceptability scores were greater for the barrow vs. gilt.

\section{Discussion}

The NRC [27] recommends $1.12 \%, 0.97 \%, 0.84 \%$, and $0.71 \%$ of total lysine concentrations with a fixed energy density of $3.30 \mathrm{Mcal}$ $\mathrm{ME} / \mathrm{kg}$ for the diets for the growing-finishing pigs with a medium-high lean-gain genetic potential weighing 25-50, 50-75, 75100 , and $100-135 \mathrm{~kg}$, respectively. The energy concentrations of all the experimental diets (3.25 to $3.35 \mathrm{Mcal} \mathrm{ME} / \mathrm{kg}$ ), as well as the 
Table 3. Performance of the finisher pigs reared on varying planes of nutrition during the grow-finish period

\begin{tabular}{|c|c|c|c|c|c|c|c|c|c|c|c|c|c|}
\hline \multirow{2}{*}{ Item } & \multicolumn{2}{|c|}{ High plane (HP) $)^{1,2)}$} & \multicolumn{2}{|c|}{ Medium plane (MP) ${ }^{1,3)}$} & \multicolumn{2}{|c|}{ Low plane $1(\text { LP1 })^{1,4)}$} & \multicolumn{2}{|c|}{ Low plane $2\left(\right.$ LP2) ${ }^{1,5)}$} & \multirow{2}{*}{ SEM } & \multicolumn{4}{|c|}{ Contrast } \\
\hline & B & G & B & G & B & G & B & G & & LP:HP & LP:MP & LP1:LP2 & B:G \\
\hline \multicolumn{14}{|l|}{ Phase I } \\
\hline Initial Wt (kg) & $71.9 \pm 1.4$ & $69.8 \pm 1.4$ & $71.3 \pm 1.3$ & $70.2 \pm 1.4$ & $74.1 \pm 1.4$ & $72.0 \pm 1.3$ & $75.2 \pm 1.5$ & $73.2 \pm 1.3$ & - & 0.05 & 0.05 & 0.45 & 0.10 \\
\hline Days on feed & 25 & 25 & 25 & 25 & 23 & 23 & 22 & 22 & - & - & - & - & - \\
\hline Final Wt (kg) & $97.9 \pm 1.9$ & $94.2 \pm 1.8$ & $98.4 \pm 1.8$ & $91.6 \pm 1.7$ & $95.2 \pm 1.7$ & $91.9 \pm 1.5$ & $97.1 \pm 2.0$ & $92.9 \pm 1.7$ & - & 0.24 & 0.60 & 0.40 & $<0.01$ \\
\hline $\operatorname{ADG}(g)$ & $1,040 \pm 30$ & $974 \pm 29$ & $1,084 \pm 28$ & $934 \pm 28$ & $914 \pm 30$ & $863 \pm 28$ & $993 \pm 31$ & $897 \pm 27$ & - & $<0.01$ & $<0.01$ & 0.08 & $<0.01$ \\
\hline $\mathrm{ADFI}(\mathrm{kg})$ & 3.25 & 3.04 & 3.13 & 2.72 & 3.21 & 2.78 & 3.21 & 2.65 & 0.10 & 0.06 & 0.68 & 0.52 & $<0.01$ \\
\hline Gain:feed & 0.321 & 0.321 & 0.346 & 0.343 & 0.285 & 0.311 & 0.309 & 0.339 & 0.008 & 0.20 & $<0.01$ & 0.01 & 0.05 \\
\hline \multicolumn{14}{|l|}{ Phase II } \\
\hline Days on feed & $18.6 \pm 1.2$ & $21.9 \pm 1.1$ & $17.5 \pm 1.1$ & $19.7 \pm 1.0$ & $20.4 \pm 1.3$ & $22.4 \pm 1.2$ & $21.8 \pm 1.2$ & $24.3 \pm 1.1$ & - & 0.10 & $<0.01$ & 0.22 & 0.02 \\
\hline Final Wt (kg) & $118.0 \pm 1.0$ & $114.4 \pm 1.0$ & $116.7 \pm 0.9$ & $110.0 \pm 0.9$ & $115.5 \pm 1.0$ & $111.5 \pm 0.9$ & $118.2 \pm 1.1$ & $115.9 \pm 0.9$ & - & 0.29 & 0.04 & $<0.01$ & $<0.01$ \\
\hline$A D G(g)$ & $1,087 \pm 31$ & $924 \pm 30$ & $1,020 \pm 29$ & $944 \pm 28$ & $1,030 \pm 31$ & $899 \pm 29$ & $983 \pm 33$ & $932 \pm 29$ & - & 0.11 & 0.42 & 0.81 & $<0.01$ \\
\hline Days to $115 \mathrm{~kg}^{6)}$ & $165.0 \pm 1.7$ & $171.8 \pm 1.6$ & $168.1 \pm 1.5$ & $177.6 \pm 1.5$ & $173.3 \pm 1.6$ & $179.4 \pm 1.5$ & $170.6 \pm 1.7$ & $176.4 \pm 1.5$ & - & $<0.01$ & 0.12 & 0.05 & $<0.01$ \\
\hline $\mathrm{ADFI}(\mathrm{kg})$ & 3.20 & 2.81 & 3.41 & 2.76 & 2.95 & 2.62 & 3.26 & 2.80 & 0.14 & 0.45 & 0.19 & 0.12 & $<0.01$ \\
\hline Gain:feed & 0.342 & 0.330 & 0.300 & 0.342 & 0.350 & 0.343 & 0.302 & 0.333 & 0.014 & 0.76 & 0.39 & 0.06 & 0.20 \\
\hline \multicolumn{14}{|c|}{ Carcass characteristics ${ }^{7}$} \\
\hline Live Wt (kg) & $117.5 \pm 1.3$ & $115.1 \pm 1.3$ & $117.3 \pm 1.2$ & $113.6 \pm 1.3$ & $116.2 \pm 1.3$ & $112.3 \pm 1.2$ & $117.6 \pm 1.3$ & $116.8 \pm 1.2$ & - & 0.62 & 0.78 & 0.02 & $<0.01$ \\
\hline Carcass Wt $(\mathrm{kg})$ & $88.7 \pm 1.1$ & $86.9 \pm 1.1$ & $88.5 \pm 1.0$ & $85.0 \pm 1.1$ & $87.6 \pm 1.1$ & $84.8 \pm 1.0$ & $89.2 \pm 1.1$ & $88.6 \pm 1.0$ & - & 0.77 & 0.39 & 0.01 & $<0.01$ \\
\hline Dressing (\%) & $75.5 \pm 0.3$ & $75.5 \pm 0.3$ & $75.4 \pm 0.3$ & $74.9 \pm 0.3$ & $75.4 \pm 0.3$ & $75.5 \pm 0.3$ & $75.9 \pm 0.3$ & $75.8 \pm 0.3$ & - & 0.63 & 0.04 & 0.14 & 0.51 \\
\hline \multicolumn{14}{|c|}{ Backfat thickness $(\mathrm{mm})$} \\
\hline Measurement & $23.6 \pm 0.8$ & $19.8 \pm 0.8$ & $24.3 \pm 0.7$ & $19.8 \pm 0.8$ & $24.7 \pm 0.8$ & $20.5 \pm 0.7$ & $25.6 \pm 0.8$ & $21.6 \pm 0.7$ & - & 0.04 & 0.11 & 0.17 & $<0.01$ \\
\hline At $115 \mathrm{~kg}^{8)}$ & $22.9 \pm 0.7$ & $19.8 \pm 0.7$ & $23.7 \pm 0.7$ & $20.1 \pm 0.7$ & $24.4 \pm 0.7$ & $21.0 \pm 0.7$ & $24.9 \pm 0.7$ & $21.2 \pm 0.7$ & - & 0.01 & 0.09 & 0.54 & $<0.01$ \\
\hline
\end{tabular}

${ }^{11}$ Nutritional composition of each diet is shown in Table 1. Data are least squares means (LSM) or LSM \pm SEM of two replicates of 13 to 17 pigs, except for the variables of the carcass characteristics.

${ }^{2}$ Fed the HP grower phases I and II and HP finisher diets during the grower phases I and II and the entire finisher phase, respectively.

${ }^{33}$ Fed the MP grower phases I and II and MP1 finisher diets during the grower phases I and II and the entire finisher phase, respectively.

${ }^{4}$ Fed the LP grower phases I and II and MP2 finisher diets during the grower phases I and II and the entire finisher phase, respectively.

${ }^{5}$ Fed the LP grower phases I and II diets and the MP1 and LP finisher diets sequentially.

${ }^{6}$ Estimated from the final weight and ADG.

${ }^{77}$ Data are LSM \pm SEM of 25 to 29 animals. Pigs weighing $102 \mathrm{~kg}$ or less at the end of the feeding trial were not slaughtered.

${ }^{8)}$ Corrected for the indicated live weight.

B, barrow; G, gilt; SEM, standard error of mean; Wt, weight; ADG, average daily gain; ADFI, average daily feed intake.

lysine concentrations of the MP diets, used in the present feeding trial were comparable to the NRC recommendation, except that the present diets were used for wider ranges of the body weight compared to those of the NRC recommendations. With respect to the usage of the commercial grow-finish diets, the ratio of the production tonnages of the three categories of diets comparable to the grower phases I and II and finisher diets of the present study was 36:56:8 during the year of 2017 in Korea [28]. This implies that the finisher diet, including the low-lysine finisher, is minimally used in this country. As such, a MP-finisher diet was provided to the LP1 as well as the MP group during the entire finisher phase to examine the influence of the provision of the LP diet vs. MP during the grower phase on growth performance during the finisher phase. In addition, the LP2 group was provided with a finisher diet with its lysine content comparable to the NRC recommendation during the finisher phase II to compare the effects of the LP vs. MP diet. The lysine content of the finisher diet provided to the LP1 group (M2) happened to be $0.05 \%$ greater than that of the finisher diet provided to the MP and LP2 groups (M1), but the M1 and M2 finisher diets, which were selected from the MP- and LP-line diets of a same manufacturer, respectively, were evaluated as a same nutritional class by the manufacturer.

Apart from the statistical significance, an $8 \%$ reduced ADG for the LP and MP groups vs. HP group during the grower phase I and II, respectively, was associated with an $8 \%$ lower daily lysine intake for the corresponding LP and MP groups vs. HP, suggesting that the reduced $\mathrm{ADG}$ in the former is likely to have resulted from an insufficient lysine intake. Moreover, the greater ADG for the LP group vs. MP during the grower phase II was associated with a greater gain:lysine ratio for the former. Similarly, the greater ADG for the MP group vs. LP during the finisher phase I was associated with a greater gain:feed ratio for the former. These results, which were similar to the increased lysine and feed efficiencies during the compensatory growth of growing-finishing pigs in previous studies $[12,29]$, suggest that the increased $A D G$ in the aforementioned LP and MP groups resulted from a compensatory growth to make up for the reduced weight gain during the preceding phase. Moreover, the similar ADG for the LP-1 and LP-2 groups during the finisher phase II provided with the isocaloric diets containing $0.85 \%$ and $0.72 \%$ lysine, respectively, suggest that a $0.72 \%$ dietary lysine 
Table 4. Physicochemical characteristics of the longissimus dorsi muscle from the pigs reared on varying planes of nutrition

\begin{tabular}{|c|c|c|c|c|c|c|c|c|c|c|}
\hline \multirow{2}{*}{ Item } & \multicolumn{2}{|c|}{$H \mathbf{P}^{1)}$} & \multicolumn{2}{|c|}{$\mathrm{MP}^{2)}$} & \multicolumn{2}{|c|}{$\mathrm{LP}^{3)}$} & \multirow{2}{*}{ SEM } & \multicolumn{3}{|c|}{ Contrast } \\
\hline & B & $\mathbf{G}$ & B & G & B & G & & LP:HP & LP:MP & G:B \\
\hline Carcass Wt (kg) & 89.2 & 88.8 & 90.2 & 85.4 & 87.4 & 87.4 & 1.3 & 0.22 & 0.76 & 0.11 \\
\hline $\mathrm{pH}$ & 5.78 & 5.60 & 5.46 & 5.48 & 5.68 & 5.63 & 0.06 & 0.53 & $<0.01$ & 0.13 \\
\hline $\mathrm{CIE} \mathrm{L*}$ & 54.8 & 55.4 & 54.6 & 52.9 & 54.0 & 53.6 & 1.3 & 0.35 & 0.97 & 0.64 \\
\hline $\mathrm{CIE} a^{*}$ & 7.49 & 8.29 & 8.73 & 8.92 & 8.55 & 8.29 & 0.60 & 0.39 & 0.51 & 0.63 \\
\hline WHC (\%) & 62.9 & 62.9 & 64.0 & 62.6 & 67.4 & 63.8 & 0.7 & $<0.01$ & $<0.01$ & 0.01 \\
\hline Drip loss (\%) & 6.34 & 7.35 & 7.04 & 9.60 & 5.63 & 9.47 & 1.05 & 0.51 & 0.47 & $<0.01$ \\
\hline Cooking loss (\%) & 35.2 & 34.3 & 34.6 & 36.4 & 36.0 & 36.0 & 0.8 & 0.13 & 0.54 & 0.66 \\
\hline W-B SF $\left(\mathrm{kg} / \mathrm{cm}^{2}\right)$ & 2.91 & 2.57 & 2.03 & 3.21 & 3.11 & 3.10 & 0.40 & 0.37 & 0.24 & 0.41 \\
\hline Cohesiveness (\%) & 0.47 & 0.45 & 0.46 & 0.54 & 0.43 & 0.55 & 0.05 & 0.45 & 0.83 & 0.11 \\
\hline Springiness (mm) & 1.12 & 1.06 & 1.07 & 1.10 & 1.00 & 1.23 & 0.06 & 0.67 & 0.62 & 0.19 \\
\hline Gumminess (kg) & 0.59 & 0.52 & 0.49 & 0.77 & 0.64 & 0.80 & 0.10 & 0.10 & 0.37 & 0.15 \\
\hline Moisture (\%) & 72.2 & 72.9 & 72.7 & 73.6 & 73.3 & 73.1 & 0.4 & 0.12 & 0.88 & 0.17 \\
\hline Fat (\%) & 3.57 & 2.72 & 3.50 & 2.32 & 4.28 & 3.02 & 0.54 & 0.37 & 0.18 & 0.02 \\
\hline Protein $(\%)$ & 19.9 & 22.1 & 21.7 & 22.5 & 20.1 & 20.5 & 0.7 & 0.34 & 0.02 & 0.07 \\
\hline \multicolumn{11}{|c|}{ 1) Fed the HP phases I \& II grower diets and the HP finisher diet sequentially. } \\
\hline \multicolumn{11}{|c|}{${ }^{2)}$ Fed the MP phases I \& I| grower diets and the MP1 finisher diet sequentially. } \\
\hline \multicolumn{11}{|c|}{${ }^{3)}$ Fed the LP grower phases I and II diets and the MP1 and LP finisher diets sequentially. } \\
\hline \multicolumn{11}{|c|}{${ }^{1-3)}$ Data are means for five animals for both $B$ and $G$. } \\
\hline
\end{tabular}

Table 5. Sensory quality attributes of the longissimus dorsi muscle from the pigs reared on varying planes of nutrition ${ }^{1)}$

\begin{tabular}{|c|c|c|c|c|c|c|c|c|c|c|}
\hline \multirow{2}{*}{ Item } & \multicolumn{2}{|c|}{$\mathrm{HP}^{2)}$} & \multicolumn{2}{|c|}{$\mathrm{MP}^{3)}$} & \multicolumn{2}{|c|}{ LP $^{4)}$} & \multirow{2}{*}{ SEM } & \multicolumn{3}{|c|}{ Contrast } \\
\hline & B & G & B & G & B & G & & LP:HP & LP:MP & G:B \\
\hline \multicolumn{11}{|l|}{ Fresh muscle } \\
\hline Color & 8.10 & 7.71 & 7.96 & 7.64 & 7.83 & 7.28 & 0.21 & 0.10 & 0.25 & 0.02 \\
\hline Aroma & 7.76 & 7.60 & 7.58 & 7.73 & 7.60 & 7.19 & 0.14 & 0.06 & 0.08 & 0.25 \\
\hline Off-odor & 7.60 & 7.36 & 7.51 & 7.70 & 7.41 & 7.07 & 0.14 & 0.11 & 0.02 & 0.27 \\
\hline Drip & 7.49 & 7.09 & 7.81 & 7.60 & 7.88 & 7.12 & 0.28 & 0.45 & 0.47 & 0.06 \\
\hline Marbling & 7.78 & 7.02 & 7.64 & 7.07 & 7.66 & 7.18 & 0.35 & 0.95 & 0.85 & 0.04 \\
\hline Acceptability & 7.87 & 7.41 & 7.67 & 7.28 & 7.91 & 7.03 & 0.22 & 0.45 & 1.00 & $<0.01$ \\
\hline \multicolumn{11}{|l|}{ Cooked muscle } \\
\hline Color & 7.71 & 7.53 & 7.50 & 7.21 & 7.56 & 7.36 & 0.10 & 0.11 & 0.32 & 0.01 \\
\hline Aroma & 7.66 & 7.68 & 7.69 & 7.56 & 7.88 & 7.77 & 0.09 & 0.10 & 0.04 & 0.32 \\
\hline Flavor & 7.73 & 7.21 & 7.36 & 7.19 & 7.71 & 7.50 & 0.15 & 0.38 & 0.04 & 0.02 \\
\hline Juiciness & 7.59 & 7.09 & 7.32 & 6.97 & 7.72 & 7.66 & 0.15 & 0.03 & $<0.01$ & 0.02 \\
\hline Tenderness & 7.80 & 7.10 & 7.52 & 6.90 & 7.76 & 7.74 & 0.22 & 0.19 & 0.02 & 0.02 \\
\hline Acceptability & 7.74 & 7.22 & 7.44 & 6.81 & 7.79 & 7.56 & 0.15 & 0.23 & $<0.01$ & $<0.01$ \\
\hline
\end{tabular}

\footnotetext{
${ }^{11}$ The sensory attributes were scored arbitrarily by 9 panelists according to a 9-ladder whole number scale such that a greater score indicates better quality

${ }^{2)}$ Fed the HP phases I \& II grower diets and the HP finisher diet sequentially.

${ }^{33}$ Fed the MP phases I \& II grower diets and the MP1 finisher diet sequentially.

${ }^{4)}$ Fed the LP grower phases I and II diets and the MP1 and LP finisher diets sequentially.

${ }^{2-4)}$ Data are means for five animals for both $B$ and $G$.

HP, high plane; MP, medium plane; LP, low plane; B, barrow; G, gilt; SEM, standard error of mean.
}

content, which is similar to the NRC [22] recommendation (0.71\% for $100-135 \mathrm{~kg}$ pigs), is probably enough for the finishing pigs weighing approximately $95 \mathrm{~kg}$ or greater.
When the dietary lysine:calorie ratio or the plane of nutrition is lower than the optimum, the rate of protein (lean) deposition as well as weight gain decreases, but the fat deposition rate usually 
increases [30, 31]. The 4.5 and 6.5 more days for the MP and LP groups vs. HP to reach a $115-\mathrm{kg}$ market, respectively, in the present study were consistent with the results in the literature regarding the effects of the plane of nutrition $[2-4,32]$. Furthermore, the greater backfat thickness for the LP vs. HP group was also consistent with the results of previous studies $[30,32]$ as well as the report of Seo [33] in which the backfat thickness was greater in the market pigs reared on the low plane of nutrition than in those reared on high-plane nutrition. It thus seems evident that both the more days required to reach the market weight and the greater backfat thickness for the LP vs. HP group resulted from the lower dietary lysine:ME ratio for the former.

The effects of provision of a low-lysine diet during the grower phase on the growth rate during the subsequent finisher phase and the backfat thickness reported in the literature vary depending on the dietary lysine concentration as well as the duration of the low-lysine diet. In the studies of Castell et al. [30] and Kerr et al. [34], the backfat thickness of the pigs reared on the low-lysine diets during the entire grow-finish period was greater than that of the pigs fed the diets with optimal lysine:calorie ratios. The pigs fed the low-lysine diet had a lower ADG and a greater backfat thickness than those on the diet with a normal lysine concentration during the grower phase in the studies of Fabian et al. [18, 19] and Millet et al. [29, 35] as well. However, when both groups of pigs were placed on a diet with an optimal lysine:calorie ratio during the finisher phase, the former exhibited a backfat thickness equal to that of the latter at the end of the finisher phase as a result of a compensatory lean growth in these studies. These results, however, cannot be directly compared with those of the present study, because the low-lysine diets in Fabian et al. $[18,19]$ and Millet et al. $[29,35]$ were $36 \%-55 \%$ and $20 \%-30 \%$ lower than those of the control diets, respectively, whereas in the present study, the differences in the lysine content between the LP and HP diets were less than $20 \%$. It thus remains to be known when the backfat deposition of the growing-finishing pigs increases due to LP like the one used in the present study.

The tendency of positive correlation between the $\mathrm{pH}$ value and fat content of LM, as well as the negative correlation between the fat and moisture contents, was consistent with the results reported by Watanabe et al. [36]. The greater $\mathrm{pH}$ value for the LP group vs. MP in the present study was thus seemingly partially associated with the greater fat content in the former, although the difference between the two groups in fat content was not significant. Nonetheless, these results, as well as the greater protein content for the MP vs. LP group, are thought to be more of a mathematical significance rather than quality, in that the numerical differences between the two groups in the $\mathrm{pH}$ value and protein content were minimal within the normal ranges for the normal pork $[14,37,38]$.
It needs to be noted, however, that the greater juiciness of cooked LM for the LP group vs. HP and MP groups is likely to have resulted from the greater WHC of fresh LM for the LP group, because $\mathrm{WHC}$ is one of the main factors enhancing the juiciness of cooked meat [38].

The intramuscular fat (IMF) content is known as a most important variable determining the sensory quality of pork, because, in general, the juiciness, flavor, tenderness, marbling, and consumers' acceptability of pork increase with the increase of IMF [38-40]. In this regard, the greater flavor, juiciness, and tenderness scores, as well as the acceptability score, for cooked LM for the barrow vs. gilt were associated with a greater IMP content of LM in the former. Similarly, the greater scores for these quality attributes for the LP group vs. MP, as well as the greater juiciness score for the former vs. HP, were associated with the numerically greatest IMP content in the former followed by MP and HP, albeit non-significant statistically. However, more studies with a greater number of LM samples are needed to confirm these sex and LP effects, not only because the LP group was no better than HP except for the juiciness score, but because the effects of the sex and PN, as well as the IMF content, on sensory quality of cooked muscle are not always consistent in different studies [27,30,40,41].

Collectively, results of the present study are suggestive of the following conclusions. Both provisions of the MP and LP diets vs. HP to the grow-finish pigs lead to a decreased growth rate resulting in an increased age to the market weight and also bring about a compensatory growth during the grower phases I and II, respectively, seemingly resulting from an insufficient lysine intake during the preceding phase. Moreover, provision of the LP diets during the grower phase also causes an increased backfat thickness, irrespectively of whether or not the LP-grower diets-fed pigs are switched to MP during the finisher phase. The eating quality of pork, however, could be improved when the grow-finish pigs are reared on LP vs. MP and possibly HP as well.

\section{Competing interests}

No potential conflict of interest relevant to this article was reported.

\section{Funding sources}

This work was supported by the Gyeongnam National University of Science and Technology (GNTECH) Grant in 2018.

\section{Acknowledgements}

The authors express their appreciation to the staff and students working in the Meat Science and Processing Laboratory of GNTECH for their participation in the physicochemical analysis and sensory evaluation of the muscle. 


\section{Availability of data and materials}

Upon reasonable request, the datasets of this study can be available from the corresponding author.

\section{Authors'contributions}

Conceptulization: Lee CY, Park MJ, Song YM.

Data curation: Lee CY.

Formal analysis: Yang BS, Choi JS.

Methodology: Kim MH, Choi JS.

Software: Lee CY, Choi JS.

Validation: Lee CY,Jin SK.

Investigation: Yang BS, Jin SK, Lee CY.

Writing - original draft: Yang BS, Lee CY.

Writing - review \& editing: Jin SK, Song YM, Lee CY.

\section{Ethics approval and consent to participate}

All experimental protocols involving animals were approved by the Institutional Animal Care and Use Committee (IACUC) of Gyeongnam National University of Science and Technology.

\section{ORCID}

Jung-Seok Choi

https://orcid.org/0000-0001-8033-0410

Sang Keun Jin

Young-Min Song

Chul Young Lee

https://orcid.org/0000-0002-8983-5607

https://orcid.org/0000-0002-4190-2997

https://orcid.org/0000-0002-4735-1268

\section{References}

1. Chung CY, Chung IB, Kwon DJ, Chung SK, Yoon HJ, Kim KS. Experiments on swine production: effects of plane of nutrition and market weight on pork quality. In: Annual research reports of National Livestock Research Institute. Korea; 1981. p. 436-76.

2. Smith JW, Tokach MD, O'Quinn PR, Nelssen JL, Goodband $\mathrm{RD}$. Effects of dietary energy density and lysine: calorie ratio on growth performance and carcass characteristics of growing-finishing pigs.J Anim Sci. 1999;77:3007-15.

3. De La Llata M, Dritz SS, Langemeier MR, Tokach MD, Goodband RD, Nelssen JL. Economics of increasing lysine:calorie ratio and adding dietary fat for growing-finishing pigs reared in a commercial environment. J Swine Health Prod. 2001;9:215-23.

4. Main RG, Dritz SS, Tokach MD, Goodband RD, Nelssen JL. Determining an optimum lysine:calorie ratio for barrows and gilts in a commercial finishing facility. J Anim Sci. 2008;86:2190-207.

5. Campbell RG, Taverner MR, Curic DM. Effect of feeding level and dietary protein content on the growth, body compo- sition and rate of protein deposition in pigs growing from 45 to $90 \mathrm{~kg}$. Anim Sci. 1984;38:233-40.

6. Campbell RG, Taverner MR, Curic DM. The influence of feeding level on the protein requirement of pigs between 20 and $45 \mathrm{~kg}$ live weight. Anim Sci. 1985;40:489-96.

7. Hill RA, Dunshea FR, Dodson MV. Growth of livestock. In: Scanes CG, editor. Biology of growth of domestic animals. Ames, IA, USA: Iowa State Press; 2003. p. 342-64.

8. Noblet J, Van Milgen J. Energy and energy metabolism in swine. In: Chiba LI, editor. Sustainable swine nutrition. Ames, IA, USA: John Wiley \& Sons; 2013. p. 23-57.

9. Ellis $\mathrm{M}$, Augspurger N. Feed intake in growing-finishing pigs. In: Lewis AJ, Southern LL, editors. Swine nutrition. 2nd ed. Boca Raton, FL, USA: CRC Press LLC; 2001. p. 447-67.

10. Ha DM, Park BC, Park MJ, Song YM, Jin SK, Park JH, et al. Effects of plane of nutrition on growth performance and meat quality traits in finishing pigs. J Anim Sci Technol. 2012;54:449-54.

11. Reynolds AM, O'Doherty JV. The effect of amino acid restriction during the grower phase on compensatory growth, carcass composition and nitrogen utilisation in grower-finisher pigs. Livest Sci. 2006;104:112-20.

12. Cloutier L, Letourneau-Montminy MP, Bernier JF, Pomar J, Pomar C. Effect of a lysine depletion-repletion protocol on the compensatory growth of growing-finishing pigs. J Anim Sci. 2016;94:255-66.

13. Bohman VR. Compensatory growth of beef cattle: the effect of hay maturity.J Anim Sci. 1955;14:249-55.

14. Lawrence TLJ, Fowler VR, Novakofski JE. Growth of farm animals. 3rd ed. Wallingford, UK: CABI; 2012.

15. Chiba LI. Effects of dietary amino acid content between 20 and $50 \mathrm{~kg}$ and 50 and $100 \mathrm{~kg}$ live weight on the subsequent and overall performance of pigs. Livest Prod Sci. 1994;39:21321.

16. Chiba LI. Effects of nutritional history on the subsequent and overall growth performance and carcass traits of pigs. Livest Prod Sci. 1995;41:151-61.

17. Whang KY, Donovan SM, Easter RA. Effect of protein deprivation on subsequent efficiency of dietary protein utilization in finishing pigs. Asian-Aust J Anim Sci. 2000;13:659-65.

18. Fabian J, Chiba LI, Kuhlers DL, Frobish LT, Nadarajah K, Kerth CR, et al. Degree of amino restrictions during the grower phase and compensatory growth in pigs selected for lean growth efficiency. J Anim Sci. 2002;80:2610-18.

19. Fabian J, Chiba LI, Frobish LT, McElhenney WH, Kuhlers DL, Nadarajah K. Compensatory growth and nitrogen balance in grower-finishing pigs.J Anim Sci. 2004;82:2579-87.

20. Ha DM, Jung DY, Park MJ, Park BC, Lee CY. Effects of 
sires with different weight gain potentials and varying planes of nutrition on growth of growing-finishing pigs. J Anim Sci Technol. 2014;56:22.

21. Hyun Y, Ellis M, Riskowski G, Johnson RW. Growth performance of pigs subjected to multiple concurrent environmental stressors. J Anim Sci. 1998;76:721-27.

22. NRC. Nutrient requirements of swine. 11th ed. Washington, DC, USA: National Academy Press; 2012.

23. CIE. Colorimetry. 2nd ed. CIE Publication No. 15.2. Vienna: Commission Internationale de l'Eclairage; 1986.

24. Lee CY, Lee HP, Jeong JH, Baik KH, Jin SK, Lee JH, et al. Effects of restricted feeding, low-energy diet, and implantation of trenbolone acetate plus estradiol on growth, carcass traits, and circulating concentrations of insulin-like growth factor (IGF)-I and IGF-binding protein-3 in finishing barrows. J Anim Sci. 2002;80:84-93.

25. Lee CH, Jung DY, Choi JS, Jin SK, Lee CY. Effects of the plane of nutrition on physicochemical characteristics and sensory quality traits of the muscle in finishing pigs. Korean J Food Sci Anim Resour. 2014;34:516-24.

26. Jin SK, Kim IS, Hur SJ, Hah KH, Kim BW. Effects of feeding period on carcass and objective meat quality in crossbred longissimus muscle.J Anim Sci Technol. 2004;46:811-20.

27. Park MJ, Ha DM, Shin HW, Lee SH, Kim WK, Ha SH, et al. Growth efficiency, carcass quality characteristics and profitability of 'high'-market weight pigs. J Anim Sci Technol. 2007;49:459-70.

28. MAFRA. Statistics. Korea: Ministry of Agriculture, Food and Rural Affairs. 2018. http://www.mafra.go.kr. Accessed 5 Nov 2018.

29. Millet S, Langendries K, Aluwe M, De Brabander DL. Effect of amino acid level in the pig diet during growing and early finishing on growth response during the late finishing phase of lean meat type gilts.J Sci Food Agric. 2011;91:1254-8.

30. Castell AG, Cliplef RL, Poste-Flynn LM, Butler G. Performance, carcass and pork characteristics of castrates and gilts self-fed diets differing in protein content and lysine:energy ratio. Can J Anim Sci. 1994;74:519-28.
31. Mitchell AD. Impact of research with cattle, pigs, and sheep on nutritional concepts: body composition and growth.J Nutr. 2007;137:711-714.

32. De La Llata M, Dritz SS, Tokach MD, Goodband RD, Nelssen JL. Effects of increasing lysine to calorie ratio and added fat for growing-finishing pigs reared in a commercial environment: I. Growth performance and carcass characteristics. Prof Anim Sci. 2007;23:417-28.

33. Seo JT. Suggestions for the improvement of pork quality and case reports on quality pork producers (published in Korean). Kor J Swine Res. 2016;45:84-111.

34. Kerr BJ, McKeith FK, Easter RA. Effect on performance and carcass characteristics of nursery to finisher pigs fed reduced crude protein, amino acid-supplemented diets. J Anim Sci. 1995;73:433-40.

35. Millet S, Aluwe M. Compensatory growth response and carcass quality after a period of lysine restriction in lean meat type barrows. Arch Anim Nutr. 2014;68:16-28.

36. Watanabe G, Motoyama M, Nakajima I, Sasaki K. Relationship between water-holding capacity and intramuscular fat content in Japanese commercial pork loin. Asian-Aust J Anim Sci. 2018;31:914-8.

37. Warner RD, Kauffman RG, Greaser ML. Muscle protein changes post mortem in relation to pork quality traits. Meat Sci. 1997;45:339-52.

38. Joo ST, Kim GD. Meat quality traits and control technologies. In: Joo ST, editor. Control of meat quality. Kerala, India: Research Signpost; 2011.p. 1-29.

39. Papanagiotou P,Tzimitra-Kalogianni I, Melfou K. Consumers' expected quality and intention to purchase high quality pork meat. Meat Sci. 2013;93:449-54.

40. Channon HA, D'Souza DN, Dunshea FR. Developing a cuts-based system to improve consumer acceptability of pork: Impact of gender, ageing period, endpoint temperature and cooking method. Meat Sci. 2016;121:216-27.

41. Choi JS, Jin SK, Lee CY. Assessment of growth performance and meat quality of finishing pigs raised on the low plane of nutrition.J Anim Sci Technol. 2015;57:37. 